\title{
Religion on divergence: A case study of Prophet Muhammad' approach
}

\author{
Muhammad Shahbaz Manj \\ Assistant Professor \\ Department of Islamic Studies \\ University of Sargodha, Sargodha, Pakistan
}

\begin{abstract}
Today world is facing various kinds of clash and conflicts, and divergences. It has an excessive need to resolve these divergences, in order to establish peace and harmony within the human race. Diverse efforts are being made to attain the goal of serenity and harmonization in this regard. Sirah of Prophet Muhammad (Peace be upon him) is a precious connote to add on the subject. This study provides a inclusive glance into Prophet Muhammad's behavior on arbitration in conflicts and divergences s. It concludes that Prophet Muhammad had exclusive approach and methods to decide clashes and divergences. It come $s$ to light the vibrant and potential of sirah to resolute the present day divergence and clashes within Muslims and Muslim and none Muslim communities of the world.
\end{abstract}

Key words : Divergence, Prophet Muhammad, Sirah, approach, present world, conflict resolutions. 